\title{
«Obra toda tejida de una admirable variedad de cosas»: la écfrasis en El Bernardo de Balbuena
}

\section{«Obra toda teijida de una admirable varie- dad de cosas»: the ekphrasis in El Bernardo of Balbuena}

\author{
Martín Zulaica López \\ Universidad de Navarra \\ ESPAÑA \\ mzulaica.4@alumni.unav.es
}

[Hipogrifo, (issn: 2328-1308), 4.1, 2016, pp. 171-181]

Recibido: 25-11-2015 / Aceptado: 07-03-2016

DOI: http://dx.doi.org/10.13035/H.2016.04.01.11

Resumen. La écfrasis ha suscitado el interés de la crítica literaria reciente como clave de interpretación poética. Comprobaremos su particular presencia en El Bernardo de Balbuena, señalado por Frank Pierce, junto a La Araucana y La Cristíada, como uno de los tres grandes poemas de la épica española. En este poema barroco la écfrasis va a alcanzar su mayor desarrollo conviertiéndose en la principal articuladora del discurso. Siendo muestra de un periodo literario en que la acción, el progreso narrativo, pierde relevancia respecto de otros elementos literarios, como el descriptivo.

Palabras clave. Écfrasis, épica, El Bernardo, Bernardo de Balbuena.

Abstract. The ekphrasis has attracted the recent literary criticism as a key for poetic interpretation. We will check her particular presence in El Bernardo of Balbuena, noted by Frank Pierce, together with La Araucana and La Cristíada, as one of the three great Spanish epic poems. In this baroque poem, the ekphrasis will achieve the greater development in the genre becoming a major articulator of the text. Being a sample of a literary period where the action, the narrative progress, loses relevance in favor to other literary elements, as the descriptive.

1. El presente trabajo se enmarca dentro del proyecto Proyecto I+D del Ministerio de Economía y Competitividad FFI2012-32231: Formas de la Épica Hispánica: Tradiciones y Contextos Históricos II; y forma parte de mi tesis doctoral becada por la Asociación de Amigos de la Universidad de Navarra. 
Keywords. Ekphrasis, Epic, El Bernardo, Bernardo de Balbuena.

En la crítica literaria reciente la figura retórica de la écfrasis ha suscitado gran interés como clave de interpretación poética y se ha tratado de establecer su posición en el campo literario. En la segunda mitad del siglo XX el término se empleaba generalizadamente para referir la descripción poética de obras de arte pictóricas o escultóricas ${ }^{2}$. Sin embargo, como han explicado recientemente diversos autores (Pineda, Lozano Renieblas, Mesa Sanz o Agudelo) ${ }^{3}$ el término écfrasis tuvo en la Antigüedad un significado distinto a éste 4 . En su sentido original la écfrasis, en latín descriptio, consiste en «la descripción detallada de una persona o de un objeto»

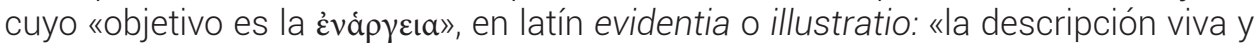
detallada de un objeto», que hace «que se compenetre el público con la situación del testigo presencial $»^{5}$. Es decir, se trata de descripciones con un estatus poético tal que logran traer lo descrito a los ojos del receptor. En el apartado dedicado a la evidentia por Lausberg, se distinguen varias clases de la misma en función de los objetos de la descripción: personas, cosas, estados, lugares, etc. Además se deben incluir también como écfrasis las de acciones siempre que éstas se ofrezcan en un marco de simultaneidad. Algo que puede sorprender en nuestro paradigma literario actual en que el discurso narrativo, el que presenta acciones, funciona en oposición respecto del descriptivo. Sin embargo la écfrasis, dice Lozano Renieblas, tal como es definida por los tratadistas antiguos, «desconoce las barreras entre lo que hoy conocemos como narración y descripción» ${ }^{6}$. Mercedes Blanco ha estudiado en su Góngora heroico la trabazón diegética de las Soledades. Ha observado que su protagonista peregrino no va a ningún lugar, concluyendo que precisamente por ello todo cuanto ve, los discursos que oye, adquieren interés por sí mismos. La descripción adquiere de este modo un estatus privilegiado en el texto?. Ha dado así en hablar de éstas como una narración sin fábula, un relato no concebido en función de una meta. Pero el poema de Góngora no es una obra aislada, sino que responde a un momento de la historia de la literatura en que la riqueza argumental pierde importancia frente a otros elementos. En el caso de El Bernardo, publicado en 1624, se camina en la misma dirección que en las Soledades pero por un sendero diferente. La fábula central que alienta el poema está clara, la batalla de Roncesvalles. Pero va a quedar difuminada por otro elemento, la sobreabundancia descriptiva. Podríamos decir que el suspense va a desaparecer del ánimo del lector, quedando éste tan perdido en su lectura como el peregrino errante de Góngora en su silva.

\footnotetext{
2. Así entendían el término: Spitzer, 1955 o Kurman, 1974; y lo emplean en estudios de temática afín a la de éste: Guillén, 1995 o Vilà, 2005.

3. Pineda, 2000; Lozano Renieblas, 2005; Mesa Sanz, 2010; Agudelo, 2011.

4. Algo de lo que da cuenta el trabajo de Ruth Webb de 1999 y su título parlante: «Ekphrasis Ancient and Modern: the Invention of a Genre».

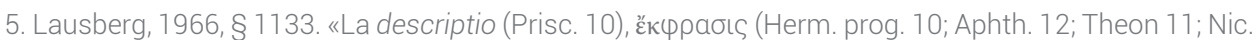
Soph. 12) es la descripción detallada de una persona o de un objeto»; Lausberg, 1966, § 810.

6. Lozano Renieblas, 2005, p. 31.

7. Blanco, 2012, p. 140.
} 
Peculiaridades que bien pueden hacer de engarce entre la narrativa barroca y la novela canónica del siglo XX8.

\section{OBRA TODA TEJIDA DE UNA ADMIRABLE VARIEDAD DE COSAS}

La écfrasis, que había sido un elemento de enorme relevancia en las epopeyas de la antigüedad clásica tales como la llíada o la Eneida, fue imitada en el Renacimiento en las obras de Boyardo o Ariosto, que son el gran precedente de Balbuena. Sin embargo, el desarrollo que va a alcanzar este recurso en El Bernardo es mucho mayor al que encontramos en estos modelos. El poema suscitó entre sus contemporáneos palabras elogiosas por parte de otros escritores como Mira de Amescua (firmante de la aprobación de El Bernardo), o Lope en el Laurel de Apolo. Y en un itinerario de olvidos y restituciones a través de los siglos, las escucharemos también por boca de Nicolás Antonio, Quintana, Lista, Ticknor o Menéndez Pelayo9. Para este último El Bernardo era el «mejor [poema] de su género en castellano», el libro de caballerías en verso, frente a los de autores como Barahona de Soto (Las lágrimas de Angélica) o Lope de Vega (La hermosura de Angélica); y constituiría «la mejor imitación del Ariosto» ${ }^{10}$. Del mismo modo, Frank Pierce lo señaló como una de las tres cumbres de la épica áurea nacional ${ }^{11}$. Sin embargo, lo realmente interesante para nosotros es que todos estos comentaristas y críticos coincidieron siempre en destacar, por su eminencia, una característica del poema, la del virtuosismo descriptivo ${ }^{12}$, con

8. Pues conecta con el predominio de la experiencialidad frente a la acción (piénsese en autores como Proust, Mann o Joyce). En estas obras no importan tanto la relación de sucesos y el argumento, como la perspectiva y el punto de vista con que se relatan, la vivencia de éstos por los personajes. La fenomenología de la percepción pasa a un primer plano y se convierte en un elemento de gran productividad. (Fludernik, 1996).

9. Balbuena, El Bernardo, f. 2v.; Lope de Vega, Laurel de Apolo, silva II, vv. 111-124. También Cervantes elogió a Balbuena en el Viaje al Parnaso, capítulo II, vv. 205-207, pero no por El Bernardo, todavía sin publicar. Nicolás Antonio, Bibliotheca hispana nova, vol. 1, p. 221; Quintana, Poesías selectas castellanas. Segunda parte. Musa épica , p. 75; Lista, 2007, p. 10; Ticknor, 1863, pp. 479; Menéndez Pelayo, 1905, p. CXLIII.

10. El erudito montañés agrupa en sus Orígenes de la novela los libros de caballerías castellanos junto a los poemas imitadores de los romanzi italianos por su temática común. Algunos hechos que permiten sostener esta opción crítica son: la prosificación de la obra de Boyardo por Pedro López de Santa Catalina con el título de Espejo de caballerías (1525-1527), presentada al público español (en sus condiciones físicas) como un libro de caballerías castellano o, años después, la versificación llevada a cabo por Bernardo Tasso, padre de Torcuato, al traducir la obra de Garci Rodríguez de Montalvo bajo el título de Amadigi (Martín Romero, 2009).

11. Los otros textos escogidos en su opus magnum de 1961 son La Cristíada, de Hojeda y La Araucana, de Ercilla. Hay quien incluso se ha atrevido a decir que es una obra admirada por todos cuantos la leen, lamentando que son pocos quienes lo han hecho. (Perelmuter, 1995).

12. Así, por ejemplo, han hablado sobre sus descripciones: Nicolás Antonio, Bibliotheca hispana nova, vol. 1, p. 221: «descriptionum elegantia, geographicae astronomicaequae rei locorum pulcherrima tractatione, miraque exprimendi, fereque oculis subjiciendi»; Lista, 2007, p. 11: «Sus cuadros son extensos, los objetos de que los llena numerosos, su imaginación fecunda los halla en abundancia y su musa pródiga los esparce con suma libertad y lozanía»; Ticknor, History of Spanish Literature, p. 479480: «many of the descriptions are rich and beautiful»; o Menéndez Pelayo, 1911, p. 57: «las facultades 
un defecto principal, la monstruosa extensión que alcanza, pues «abusa del don que tenía para inventar, y del mayor que aún le asistía para versificar y describir» ${ }^{13}$. Balbuena encabezó El Bernardo con «tal vez el prólogo crítico más importante de toda la épica del Siglo de Oro» ${ }^{14}$, en el que dio cuenta de cuanto había tratado de poner en práctica en su poema ${ }^{15}$. Así, no podía faltar en éste una mención al ejercicio de écfrasis que había desarrollado siguiendo los poemas clásicos, para engalanar la historia de Bernardo en Roncesvalles e ilustrar a sus lectores:

con lo más florido de las antigüedades y nobleza de España, descripciones de lugares, montes, ríos y fuentes, castillos y palacios suntuosos, con una casi universal geografía del mundo, sembrada artificiosamente por él, y las costumbres más notables de sus naciones y aquellas que, por haber dejado vistoso rastro de sí en las memorias de las gentes, más dignas juzgué de ser celebradas ${ }^{16}$.

Todas estas descripciones anunciadas por Balbuena, obviando su carácter epistémico por el cual están en buena medida al servicio de la geografía y otras ciencias afines, están destinadas a satisfacer el apetito estético de los lectores con su belleza y poseen un lugar propio en la estructura del poema. No era indiferente incluirlas o no hacerlo. Esto mismo lo señalaron las poéticas clásicas diciendo que la écfrasis formaba parte del ornatus del poema, «precisamente por rebasar la evidentia de lo necesario» ${ }^{17}$, siendo por ello muy propia del estilo elevado. Balbuena, consciente de ello y movido por el deseo de dar a su poema la mayor suntuosidad y belleza, va a hacer de El Bernardo una gran écfrasis. Y considerando que su obra había sobrepasado al resto en este aspecto, mandó estampar en la portada, bajo el título del poema, el siguiente texto:

Obra toda tejida de una admirable variedad de cosas, antigüedades de España, casas y linajes nobles della, costumbres de gentes, geográficas descripciones de las más floridas partes del mundo, fábricas de edificios y suntuosos palacios, jardines, cazas y frescuras

De esta manera la puerta de entrada a la obra -pues esto es etimológicamente la portada- disponía a los lectores a la contemplación de la admirable variedad de cosas anunciada. Y ellos, efectivamente, se encontraban con ellas al pasar las páginas, pues las descripciones copan casi un tercio de las octavas del poema18. No podemos dar aquí, por cuestiones de espacio, el catálogo completo de las mis-

descriptivas del Abad de la Jamaica eran casi iguales a las del Ariosto, y por de contado superiores a las de cualquier poeta nuestro».

13. Quintana, Poesías selectas castellanas. Segunda parte. Musa épica, p. 76.

14. Pierce, 1968, p. 254.

15. Lara Vilà y Marcela Londoño han editado otros quince prólogos de forma conjunta en apéndice a Vega y Vilà, 2010, pp. 271-312.

16. El Bernardo, Prólogo, s.n

17. Lausberg, 1966, $\S 810$.

18. La tradición de los estudios descriptivos de la poesía épica grecolatina tiende a separar del resto de las descripciones el uso de los símiles extensos por sus características funcionales propias. Es por ello que no los hemos incluido en este cómputo. Sobre ellos puede verse Moulton, 1977. 
mas; pero sí ofrecer algunos ejemplos de cada categoría en función del objeto de descripción:

- Retratos de personajes que ocupan cerca de 300 octavas. Como los de: Alcina (I, 44-45), Alancredo (I, 140-146), el jayán Fracaso (III, 38-39), Angélica (XIV, 129-131; XVIII, 172-176) o Ascanio (XXIV, 139-165).

- Descripciones de armas que van de lo material a lo heráldico y que forman parte de la prosopografía de los caballeros: Morgante (XIII, 33-35; con las armas de Alcídes XXI, 188-195), Caballero del luto (XVII, 146-147), Bernardo (II, 75-80; XVII, 159-162; XXIV, 37-41); o de catálogos de caballeros, dénombrement épique: campos español (VIII, 26-111), francés (XXIV, 135-193) y moro (XXIII, 105-132) ${ }^{19}$. En conjunto unas 240 octavas.

- Descripciones de obras de arte: el hilado de las Parcas (II, 19-91), el manto de Iberia (II, 187-218), o la tapicería de la sala de la fuente de las maravillas (XIX, 120-122; 145-226). Con un total cercano a las 180 octavas.

- Descripciones arquitectónicas de palacios, castillos, cámaras, ermitas, cavas, chozas, torres... que en El Bernardo, como en la tradición literaria caballeresca, se escinden en dos grupos: los espacios de la vida real, que apenas suman 30 octavas como los castillos de Arcandro $(V, 121-123)$ y de Sansueña (V, 197-202) o el convento de San Basilio (XII, 52); y los espacios maravillosos, que alcanzan las 270: castillo de Morgana (I, 53-64, 208-233), palacios de Galiana (V, 160-185), tienda mágica de Arleta (VII, 104-105, 113-115), ermita de San Vicente (XII, 105-106, 115-137), castillo de Angélica y Medoro (XIV, 18-26), cava mágica de Tlascalán (XVIII, 124134, 147-159), castillo del Carpio (XX, 198, 204-213; XXI, 7-11, 24-25)20.

- Descripciones de objetos maravillosos que alcanzan un cómputo de 110 octavas: carro del triunfo del amor (X, 165-167), el espejo mágico de Clemesí (XXI, 26-32, 39-95) o los objetos del alquimista Tlascalán (XVIII, 135-146).

- Descripciones de lugares: como las geográficas de Asia (XIV, 46-58, 97122), Europa (XV, 165-186; XVI, 7-186, este último libro dedicado a España) y América (XVIII, 102-122); topográficas, como la del valle del Ebro - que se presenta como un locus amoenus- (II, 122-129, 165-167); o las descripciones astronómicas de los magos Tlascalán (XVIII, 161-164) y Malgesí (XVII, 1-32). Un derroche de conocimiento, a lo largo de casi 350 octavas, que dignifica a Balbuena como conocedor de la ciencia cartográfica moderna o de la teoría heliocéntrica ${ }^{21}$.

19. Compárese con las relaciones en el Cantar de Mio Cid: en la batalla de Alcocer (vv. 735-743) o en la descripción de la mesnada engalanada del Cid en Valencia (vv. 1991-1998). Lo que en el Cantar ocupa un número de 8 o 9 versos, en el Bernardo se extiende a lo largo de 75 octavas, o sea, 600 versos. En el Cantar el catálogo es una suma de nombres mientras que El Bernardo es una suma de descripciones. 20. Sobre esta distinción y su importancia funcional véanse los trabajos de Neri, 2007a y 2007b.

21. Sobre la restauración de la capacidad de exploración del mundo de la épica antigua gracias al desarrollo de la ciencia cartográfica moderna y el intento de autodignificación de los poetas por esta vía, 
- Descripciones de sucesos dadas con carácter de simultaneidad ${ }^{22}$, que suman casi 70 octavas, como la procesión de un carro fúnebre (VI, 169173); la tormenta mágica convocada por Malgesí (XIII, 138-150); el desfile de los locos de fortuna visto por Bernardo (XVII, 36-62); la metamorfosis del aya Gravinia en un rosal (XI, 94-97); la rota de Roldán en el ejército español (XXIV, 125); o la alegoría de la vida de necios y prudentes cruzando las puertas del palacio de Temis (XIV, 153-165).

Ante tal cantidad de descripciones debemos preguntarnos en qué medida influye esto en la eficacia narrativa del poema, teniendo en cuenta que una de las quejas más frecuentes de los lectores de El Bernardo es la de su enorme extensión ${ }^{23}$. John Van Horne se planteó esta cuestión llegando a conclusiones que resultan interesantes para nuestro trabajo. Llevó a cabo una comparación entre el número de versos de El Bernardo con el de otros poemas del mismo género y encontró que éste no variaba de manera considerable. Frente a los 40000 versos de El Bernardo, el Orlando furioso tiene 38728 y el Orlando innamorato 35432. Lo que lo llevó a clasificar las octavas de El Bernardo y de otras obras teniendo en cuenta la forma del discurso predominante en cada una, para poder analizar de un modo global si había diferencias en el desarrollo narrativo entre los textos:

The Furioso has approximately 150 stanzas of moral introductions, 523 stanzas of secondary stories, and 208 stanzas of catalogues and the like, or in all, some 881 stanzas of material quite foreign to the progress of the action among characters already introduced. In the Bernardo I count 1330 stanzas of secondary stories and 755 of catalogues, making some 2085 in all ${ }^{24}$.

Van Horne concluyó que el motivo de que la lectura de El Bernardo fuera tan amena a críticos y poetas, al mismo tiempo que tan dilatada y causante de quejas, se debía a la inclusión de tramas secundarias y de enumeraciones ('catalogues'), puesto que estos apartarían del avance de la acción principal en 2085 de las 5000 octavas. Algo que es acertado en parte, pero que pensamos debe replantearse. Es aquí donde entra en juego la écfrasis (traída a gala por el propio Balbuena en su portada), pues va a condicionar enormemente la constitución textual del poema.

acúdase a los capítulos X y XI dedicados al tema por Mercedes Blanco, 2012.

22. La descripción de hechos, procesos o acciones es una categoría recogida por los tratadistas antiguos (Lausberg, 1966, § 810). Entre estas descripciones se incluyen procesos de la vida laboral, acontecimientos bélicos, fiestas, catástrofes naturales... También la recogen bajo el término pragmatografía críticos modernos como Mayoral, p. 188. Para ahondar en ello acúdase a Van Dijk, 1975, pp. 281-284. 23. «But it has one capital defect. It is fatally long, thrice as long as the Iliad» (Ticknor, History of Spanish Literature, p. 480).

24. Van Horne, 1927, pp. 168-169. 


\section{UNA ESCLAVA EN EL TRONO: DESCRIPTIO ANCILLA NARRATIONIS}

Si analizamos el epígrafe de Van Horne dedicado a recoger los Catalogues and reviews observaremos que todos ellos poseen carácter descriptivo. Algunos de los que señala son:

The voyage of Malgesí, Morgante, Orimandro, and Reinaldos on the flying ship leads to the review of Northeast Europe, Greece, and central Europe (XV, 165-186), [...] Iberia's tapestries embody the genealogies of great Spanish families (XIX, 132226). Clemesí describes to Bernardo his descendants (XXI, 48-95). The Moorish army is described (XXIII, 104-132), and also the French army (XXIII, 134-193).

Es decir, el motivo por el que estos elementos comprometen el progreso narrativo no es su estructura catalográfica, sino su condición descriptiva. Por ello, no consideramos justificado que el resto de las descripciones, las que no son enumeraciones en forma alguna, no sean consideradas por Van Horne como elementos capaces de demorar el tiempo, el progreso narrativo. Gerard Genette ha profundizado en las diferencias que existen entre la descripción y la narración. Dos términos que en la actualidad tienden a concebirse como una oposición en torno a la progresión del relato cuando realmente no lo son. Advierte que, en realidad, desde el punto de vista de los modos de presentación, tanto la descripción como la narración ponen en juego los mismos recursos del lenguaje pero sobre objetos distintos: las cosas o los eventos ${ }^{25}$. Las descripciones (como ha sintetizado Byre a propósito de la épica homérica) ${ }^{26}$ no son de por sí digresivas, sino constituyentes del universo espaciotemporal de la fábula ${ }^{27}$. Ahora bien, dejando claro que son elementos diegéticos, esto no supone que las descripciones no comprometan la tensión narrativa. Es lo que Genette trata de explicar al hablar de la descripción como la ancilla narrationis. El hecho de que aunque no pueda haber narración sin descripción y sí al revés, no abunda la literatura exclusivamente descriptiva, y sí en cambio la hay muy puramente narrativa ${ }^{28}$. La descripción es una esclava totalmente necesaria, pero con todo, totalmente sumisa a la narración. Es decir, la proporción descriptiva de un discurso narrativo no puede ser total, pues en tal caso no habría fábula. Podríamos tratar de sintetizar esto asumiendo que la diégesis puede hacerse morosa principalmente por dos vías. La primera de ellas es la vía digresiva, o excurso, que supone etimológicamente el encaminamiento narrativo por una trama secundaria. Pero existe una segunda vía que podríamos llamar retentiva, que provoca una deceleración sin abandonar el camino tomado. Como si el escritor, vuelto músico, hubiera tomado un metrónomo y lo hubiese regulado para marcar un tempo largo. En El Bernardo nos encontramos con que la diégesis de objetos (la descripción) se expande de manera desorbitada, produciendo este último efecto. Tenemos un

27. Si bien, el término digresión es inevitablemente controvertido en la crítica literaria, pues hay quien lo continúa aplicando indiscriminadamente a cualesquiera descripciones de objetos, escenas o personas, sin restringirlo a las que presenten una acción narrativa externa a la de la obra (Austin, 1966, p. 299). 28. Genette, 1966, p. 157 
ejemplo muy significativo en los ejercicios de écfrasis de los ejércitos de diferentes poemas en los que se presenta el desfilar con una visión esencialmente estática. En El Bernardo la bella Florinda está viendo desfilar el campo español frente a Sansueña, desde un mirador situado en lo más alto de una torre, y pide a Altero que le describa a los soldados. Algo que éste hace al completo en casi setecientos versos (VIII, 26-111) 29. Este episodio, en diálogo con la tradición clásica de la ticoscopia - revista desde la muralla-, está escrito a imitación del de la llíada en que Helena describe a Príamo a los héroes aqueos desde una torre cercana a las murallas de Troya (III, 161-242). El otro gran modelo lo encontramos en el Orlando furioso con la descripción que hacen de los ejércitos británicos a Ruggiero (VIII, 77-89). Pero en el poema homérico, la descripción apenas ocupa ochenta versos y en el italiano es cercana a los cien, de forma que los números hablan por sí solos ${ }^{30}$. Mas no pensemos que Balbuena lo hace como una rara avis al margen de su paradigma literario inmediato, sino perfectamente inserto en él. «L'époque baroque s'est signalée par une sorte de prolifération de l'excursus descriptif [...] et qui a fini par détruire l'équilibre du poème narratif à son déclin $»^{31}$. El auge de la écfrasis responde a un momento de la evolución literaria en que la riqueza y variedad argumental pierde importancia en el conjunto del poema. Van Horne considera acertadamente que las descripciones no suponen necesariamente una interrupción de la diégesis del poema. Pero, aunque pueda afirmar que son aburridas en alguna ocasión ${ }^{32}$, se olvida de incluirlas en sus cómputos (sólo incluye las catalográficas) y deja de lado tal vez el elemento más característico de la obra. Por ello, tras registrar todas las descripciones del poema, hemos llevado a cabo un nuevo recuento, pudiendo concluir que en El Bernardo hay 1550 octavas de carácter descriptivo, sean o no catalográficas. Lo que unido a las mentadas 1330 que incluyen historias secundarias hacen que, de las 5000 octavas del poema, aproximadamente unas 2880 (algo más de la mitad del poema) demoren la diégesis. Un número que frente a las 881 del Orlando Furioso, en recuento de Van Horne, resulta pasmoso y que nos permite extraer nuestras conclusiones. Frente a estos datos se logra dar justificación a los testimonios de lectura existentes de El Bernardo. Estos testimonios coincidían en valorar la gran calidad poética de Balbuena, especialmente en las descripciones,

29. Esta es el segunda de las tres técnicas que Philipe Hamon, uno de los teóricos de la descripción más destacados en la actualidad, ha señalada como empleadas regularmente en las novelas realistas decimonónicas para integrar las descripciones en la diégesis: 'le regard descripteur' (se describe lo visto por un personaje), 'le bavard descripteur' (un personaje es quien describe) y 'le travailleur descripteur' (se describe la acción de un personaje). (Hamon, 1993, pp. 165-197) Además, en el caso de las obras renacentistas y barrocas, este ejercicio de introducción del discurso de los personajes es una deliberada imitación de Homero, y supone la aceptación de los criterios de Aristóteles, que había señalado a éste como el mejor de los poetas porque intervenía las menos veces posibles en sus obras dejando hablar a sus personajes y consiguiendo de ese modo una imitación directa (Poética, 1460 a).

30. Nótese que en el caso de El Bernardo y el Orlando furioso la numeración es de cantos y octavas, mientras que en llíada lo es de cantos y versos.

31. Gennete, 1966, p. 157. Nótese que aquí Genette se refiere a lo descriptivo, por error redaccional, como un excurso cuando en todo el artículo se ha ocupado de apartarlo de éste.

32. «Balbuena indulged also in long, detailed, often tiresome descriptions. Morgana's palace in the first book, and the castle of fame in the second are examples» (Van Horne, 1927, p. 137). 
al mismo tiempo que criticaban su fatigosa lectura y enorme extensión. Hemos podido demostrar que estos dos juicios no solo no son contradictorios, sino que son interdependientes el uno del otro, puesto que, aislada, la habilidad descriptiva era lo mejor en El Bernardo, pero en el conjunto del poema era aquello que hacía de la obra un texto demasiado extenso. Esto supone una honda revisión de la repercusión de la figura de la écfrasis en el desarrollo diegético de la épica del barroco que nos permite contemplar la que habrá de confirmarse como nota general de la misma en el resto de los poemas españoles del periodo y señalar El Bernardo como el gran poema español de esta estética y el que más radicalmente pone en práctica sus supuestos. Hay un último elemento que viene a confirmar todo esto y que es en cierto modo una hoja de ruta para la lectura del poema. Pues Balbuena incorpora al final del libro una tabla pacientemente elaborada en la que da cuenta de todas estas hermosas creaciones. La inclusión de tablas sumarias es frecuente en los poemas épicos. Ercilla elaboró unas para La Araucana. No obstante, si se comparan ambas, se observará cómo, mientras que las de este último traen una relación de pasajes destacables del poema y la referencia a pocas descripciones, en el de Balbuena las tornas se invierten, incluyéndose muchísimas más menciones al lugar en que pueden encontrarse sus ejercicios de écfrasis (de un persona, un palacio o un ejército), que a los pasajes narrativos más estimados por el poeta. Aunque, todo sea dicho, muchas de estas referencias estén equivocadas. Así, del mismo modo que tras unos cuantos siglos Virgilio entendió que para rivalizar con Homero y crear una épica para el imperio romano tendría que sobrepasar todas las técnicas de su modelo, incluyendo la de la écfrasis ${ }^{33}$, así también Balbuena procuró superar ambos modelos tejiendo su obra con numerosísimas y preciosas descripciones. Motivo de orgullo y característica tan definitivamente personal, que quiso quedara plasmada en el frontispicio de su poema: El Bernardo, o Victoria de Roncesvalles. Obra toda tejida de una admirable variedad de cosas.

\section{BIBLIOGRAFÍA}

Agudelo, Pedro Antonio, «Los ojos de la palabra. La construcción del concepto de écfrasis, de la retórica antigua a la crítica literaria», Lingüística y literatura, 60, 2011, pp. 75-92.

Antonio, Nicolás, Bibliotheca hispana nova, Madrid, Ibarra, 1783-88, 2 vols.

Austin, Norman, «The Function of Digressions in the lliad», Greek, Roman and Bizantine Studies, 7, 1966, pp. 295-312.

Blanco, Mercedes, Góngora heroico. Las «Soledades» y la tradición épica, Madrid, Centro de Estudios Europa Hispánica, 2012.

Byre, Calvin S., «On the description of the harbor of Phorkys and the cave of the nymphs, Odyssey 13.96-112», American Journal of Philology, 115, 1994, pp. $1-13$. 
Cantar de Mio Cid, ed. Alberto Montaner Frutos, Madrid, Real Academia Española, 2011.

De Armas, Frederick A. (ed.), Ekphrasis in the Age of Cervantes, Lewisburg, Bucknell University Press, 2005.

Dijk, Teun A. Van, «Action, Action description, and Narrative», New Literary History, 6, 2, (On Narrative and Narratives), 1975, pp. 273-294.

Fludernik, Monika, Towards a 'Natural' Narratology, London, Routledge, 1996.

Genette, Gerard, «Frontières du récit», Communications, 8 (Recherches sémiologiques: I'analyse structurale du récit), 1966, pp. 152-163.

Guillén, Felisa, «Ekphrasis e imitación en la Jerusalén Conquistada», Hispania, 78, 2, 1995, pp. 231-239.

Hamon, Philipe, Du Descriptif, París, Hachette Livre, 1993.

Horne, John Van, «El Bernardo» of Bernardo de Balbuena. A Study of the Poem with Particular Attention to its Relations to the Epics of Boiardo and Ariosto and to its Significance in the Spanish Renaissance, Illinois, University of Illinois Studies in Language and Literature, vol. XII, 1, 1927.

Kurman, George, «Ecphrasis in Epic Poetry», Comparative Literature, 26, 1974, pp. 1-14.

Lausberg, Heinrich, Manual de retórica literaria. Fundamentos de una ciencia de la literatura, Madrid, Gredos, 1966.

Lista, Alberto, «Examen del Bernardo de Balbuena», Ensayos, ed. Leonardo Romero Tobar, Madrid, Fundación Manuel Lara, 2007, pp. 9-30.

Lozano Renieblas, Isabel, «La écfrasis de los ejércitos o los límites de la enárgeia», Monteagudo, 10, 2005, 3a época, pp. 29-38.

Mayoral, José Antonio, Figuras retóricas, Madrid, Síntesis, 1994.

Martín Romero, José Julio, «Poemas caballerescos italianos», en Amadís de Gaula, 1508: quinientos años de libros de caballerías, ed. José Manuel Lucía Megías, Madrid, Biblioteca Nacional y Sociedad Estatal de Conmemoraciones Culturales, 2009, pp. 259-264.

Menéndez Pelayo, Marcelino, Orígenes de la novela, vol. I, Madrid, Bailly Bailliere e Hijos, 1905.

Menéndez Pelayo, Marcelino, Historia de la poesía hispano-americana, t. I, Madrid, Librería general de Victoriano Suárez, 1911.

Mesa Sanz, Juan Francisco, «Rethorum itinera: écfrasis», Eikasia. Revista de filosofía, 32, 2010, pp. 173-196.

Moulton, Carroll, Similes in the Homeric poems, Göttingen, Vandenhocck \& Ruprecht, 1977. 
Neri, Stefano, Antología de las arquitecturas maravillosas en los libros de caballerías, Alcalá de Henares, Centro de Estudios Cervantinos, $2007 a$.

Neri, Stefano, «Lo maravilloso arquitectónico en los libros de caballerías», en De la literatura caballeresca al Quijote, dir. Juan Manuel Cacho Blecua, Zaragoza, Prensas Universitarias de Zaragoza, 2007b, pp. 383-394.

Perelmuter, Rosa, «¿Merece la pena leer el Bernardo? Lectura y lectores del poema épico de Bernardo de Balbuena.», Revista Iberoamericana, vol. LXI, 1995, 172, pp. 461-466.

Pierce, Frank, La poesía épica del Siglo de Oro, Madrid, Gredos, 1968, $2^{\text {a }}$ ed.

Pineda González, María Victoria, «La invención de la écfrasis», en Homenaje a la Profesora Carmen Pérez Romero, Cáceres, Servicio de Publicaciones de la Universidad de Extremadura, 2000, pp. 251-262.

Quintana, Manuel José, Poesías selectas castellanas. Segunda parte. Musa épica, Madrid, M. de Burgos, 1833, vol. 1.

Rosell, Cayetano, Poemas épicos I, Madrid, Rivadeneyra, 1851.

Spitzer, Leo, «The "Ode on a Grecian Urn" or Content vs. Metagrammar», Contemporary literature, 7, 1955, pp. 203-226.

Ticknor, George, History of Spanish Literature, New York, Harper \& Bros., vol. II, 1849.

Vega, Ma José y Lara Vilà (ed.), La teoría de la épica en el siglo XVI (España, Francia, Italia y Portugal), Vigo, Academia del Hispanismo, 2010.

Vilà, Lara, «Batallas más que pictóricas. Écfrasis e imperialismo en El Monserrate de Cristóbal de Virués», Silva, 4, 2005, pp. 299-325.

Webb, Ruth, «Ekphrasis ancient and modern: the invention of a genre», Word \& Image, 15, 1999, pp. 7-18. 
